\title{
Perfecting Administrative Institution to Enhance Scientific Research Capability of Graduates in Universities
}

\author{
Zhiying Wang \\ College of Life Science of Jilin Agricultural University, Changchun, 130118, China
}

Keywords: Graduate; Scientific research capability; Administrative staff; Supervisor

\begin{abstract}
The enhancement of scientific research capability is the most fundamental objective for graduate education and complies with the basic requirement for implementing the strategy of driving development by innovations. This paper takes the enhancement of scientific research capability of graduates and cultivation quality as its goals and seizes the opportunity of graduate cultivation. In combination with the practical working experience, this paper carries out research on the construction of administrative institution surrounding the three levels, namely supervisors, administrative staff and graduates, and discusses the effective channel to enhance the scientific research capability of graduates.
\end{abstract}

\section{Introduction}

Graduate education belongs to the top layer of national sequential education. Compared to undergraduate education, graduate education should focus on cultivating the research, analysis and problem-solving capability of students so that the graduates possess relatively strong scientific research capability in the field they are involved in when they accomplish their study. The scientific research capability of graduates refers to the capability required for graduates to carry out common intelligent innovative activities in his disciplinary field aiming at exploring the truth behind. In short, it refers to the capability needed for graduates to successfully accomplish their scientific research activities and tasks. It mainly includes the scientific research innovation capability, problem finding and solving capability, document collecting and processing capability, logical thinking capability, verbal expression capability and practical capability.

\section{Construction of Administrative Institution Aimed at Graduate Supervisor Level}

Currently, in the "supervisor system" graduate education and cultivation mode implemented in China, with supervisors being primarily responsible for graduate education, the role and position of supervisors in the comprehensive graduate education cannot be neglected. In the transition from learning in undergraduate stage to researching in graduate stage, the correct guidance from supervisors will contribute to graduates' avoiding detours and exploring the cutting-edge disciplinary frontier.

Regulate Supervisors' Excellent Moral Character and Rigorous Academic Style. As for university graduate education and cultivation, graduates spend most of their time following their supervisors in the path of carrying out scientific research and writing academic papers during their graduate period. In this series of activities, the supervisors' rigorous academic attitude and hard-bitten scholarship spirit are influencing their students at every moment. In the meanwhile, graduates are unconsciously influenced by their supervisors in the aspects of personal world outlook, life outlook and values; some of the supervisors' outstanding characters in academic morality and thinking will make graduates consciously continue the supervisors' thinking and behaving modes in future life and study. As a result, from the perspective of administrative institution, the graduate supervisors are required to make an exemplary conduct, teach by personal example and verbal instruction, use their own practical behaviors to demonstrate to students as well as help graduates to build correct life outlook, world outlook and values

Require Supervisors to Possess Stable Research Direction and Improve their Professional Quality Comprehensively. Stable research direction serves as a true demonstration of the 
professional quality of graduate supervisors for the reason that it requires sufficient academic influence and achievements as well as scientific research funding for an individual to occupy the research direction in one certain field. Without a stable research direction, no significant research achievement will be gained during graduate cultivation process.

Strengthen the Supervisors' Administrative Role on Professional Learning. Supervisors play an irreplaceable administrative role in the professional learning of graduates during graduate cultivation period. At the beginning when graduates are enrolled, supervisors will examine their professional knowledge reserve and inspect their personal moral characters. With the implementation of graduate cultivation courses, supervisors give graduates planning guidance on their academic research path during graduate learning process and pay attention to the thinking trends of graduates at every moment in order to make sure that they will not deviate from the social moral regulations. Before graduation, supervisors will guide and examine the graduation thesis of graduates to make sure that all the graduates can graduate successfully and give their suggestions on career occupational direction.

Emphasize the Supervisors' Role in Career Planning of Graduates. Currently, the higher education is faced with problems of rapid graduate population growth, increasingly intense market competition and fastidious but incompetent graduates. In this background, it is very necessary for supervisors to give graduates guidance on career development aspect. Supervisors have been occupied in their professional research field for a long time and accumulated a wide range and great depth in their academic research. They have the ability and duty to be fully responsible for occupational guidance on graduates and to cultivate both socialist-minded and professionally competent senior talents. They can guide students to build practical and studious learning quality, make efforts to improve comprehensive quality and become an excellent talent developing in an all-around way; instruct students to build correct occupational awareness, develop a right position, participate more social practices, understand the social development trends by practices and foster their own sense of social responsibility.

\section{Construction of Administrative Institution Aimed at Graduate Administrative Staff Level}

Currently, the majority of graduate cultivation organizations have implemented two-level administrative mode. The administrative authority is gradually moved downwards. Due to long-term influence from outdated administrative institution and ideas, there are many problems existing in current university graduate administration, which restrict the enhancement of graduates' scientific research capability. In order to solve this problem, following measures should be taken as emphasis:

\section{Expand the Graduate Administrative Autonomous Authority of College Units}

Generally, it is assumed that the graduate school serves as the university administrative department for graduates. Although each college in the university is at the same administrative level as the graduate school, the colleges should abide by the administration of university (graduate school) in the aspect of graduate administration. Rationally dividing the responsibility of the two units and effectively configuring their own authority can fully arouse the enthusiasm of college units and are of great significance to effectively improving graduates' innovation capability and enhancing graduates' comprehensive quality. As some think that power is dialectical and unified with responsibility, gaining power means undertaking corresponding responsibility.

As the graduate enrollment scale gets increasingly larger and the society has put forward stricter requirements for graduate cultivation quality, the promotion of mechanism reform should be accelerated and partial power core should be decentralized to colleges to establish more democratic, open and flexible cultivation mechanism. Graduate school carries out process evaluation administration through the aspect of macroscopic policies. In this way, colleges will possess relatively independent and autonomous graduate administrative authority and can organize, formulate and implement each teaching administrative system. In addition, colleges can realize administration over the whole process of graduate cultivation and degree awarding, such as formulation, implementation and examination of cultivation scheme, for the purpose of promoting the enhancement of graduates' scientific research capability and improvement of cultivation quality. 


\section{Improve Cultural Quality and Comprehensively Optimize the Structure of Administrative} Staff Team. The comprehensive quality of the graduate administrative department team directly influences the administration quality and efficiency as well as the graduate cultivation quality. Previous empirical administration has been far outdated for satisfying current demands. To improve administration quality and efficiency as well as adapt to the current pace of graduate education, graduate administrative staff should focus on improving their own comprehensive quality and correctly execute the degree and graduate education policies from the Ministry of Education. In combination of the actual scientific research capability and level of their own graduates, they should keep deepening the graduate education reform and innovating the cultivation mode for enhancing scientific research capability. Secondly, graduate administrative staffs are required to establish good knowledge structure and should fulfill multiple affairs for graduates in different disciplines, types and levels, such as daily teaching administration, cultivation plan examination and degree thesis administration. It is not easy to undertake this job. Therefore, graduate administrative staff must possess excellent knowledge structure to improve their administration quality and efficiency. Thirdly, graduate administrative staff should receive multi-form, multi-channel and multi-dimensional training on relevant theoretical knowledge and professional quality with specific targets and cores, such as psychology, education, management, statistics, computer application technology and official document writing. In addition, they should be encouraged to participate more in communications with other on-campus administrative staff, exchange programs with their counterparts in other universities and investigations on foreign advanced administration methods, etc.

Strengthen Service Awareness, Keep High Sense of Responsibility and Excellent Working Style. Graduate administration requires highly for time efficiency and sense of responsibility. This requires graduate administrative staff to establish their awareness of responsibility and keep a serious and rigorous attitude towards their work; stay practically-minded and weaken their consciousness of right in their working style.

\section{Construction of Administrative Institution Aimed at Graduate Level.}

Although graduates' scientific research capability is influenced by their supervisors, administrative staff and hardware conditions of the cultivation unit, the inner cause is both the basis and source for changes and development of everything and determines the properties and development trends of everything. As a result, in order to guarantee the enhancement of graduates' scientific research capability, we firstly need to find out the problems of graduates themselves, propose effective solutions and inspire the instinct of graduates.

Abandon the Wrong Concept of Setting the Degree as the Only Purpose. Currently, the purpose of many graduates for pursuing their graduate study is not to engage them into the research field in the future but more to gain the master's degree certificate. Furthermore, some even pursue graduate study for the reason that they do not want to take up a job too early. Only the remaining a few proportion of students are truly interested into scientific research. Therefore, in the studying and researching process of graduates, the majority of graduates are passive with the desire for just finishing their assignments and getting the credits

Focus on Cultivating the Capability to Find Problems. Cultivating the graduates' capability to find and solve problems is a significant objective of graduate education. Undoubtedly, it is more important for them to find problems. Einstein thinks that putting forward a problem tends to be more important than solving one. It requires innovative imagination capability to see the old problems from a new perspective, which symbolizes the true advancement of science. In the era of knowledge economy, scientific innovation is particularly vital. Graduates should follow the development process of masters' scientific thinking; explore new problems, thoughts and methods in science, which will contribute to cultivating the graduates' capability to find problems.

Lay Solid Foundation in English Proficiency and Focus on Improvement of English Capability. It is generally assumed that language is only a tool and almost irrelevant to enhancement of scientific research capability. But in fact, English is a science and discipline, which should be mastered by graduates, as a language, English serves as a major tool to gain latest academic 
information and carry out widespread academic communications. Solid English foundation and high-level professional English capability are the prerequisites for graduates to look up and read English literature and English original books skillfully as well as the basis for them to carry out discussion and communications with foreign counterparts on academic topics and viewpoints. Possessing high-level professional English proficiency is a basic skill for graduates to satisfy increasing demand by society, technology, economy and foreign exchanges. As a result, graduates should lay solid English foundation, improve their English proficiency and master the hot cutting-edge topics and problems in current academic community.

Strengthen Cultivation of Academic Paper Writing Capability. Generally, new learners meet with deficiencies in writing academic papers, such as blurry objectives, vague and general contents, unclear arrangement of ideas and loose deductions. Therefore, graduates should read more literature with high quality, communicate wither their classmates more, do more modeling and training practices as well as seek instructions from their supervisors in order to enhance their capability in writing academic papers comprehensively. They are required to grasp systematic method for looking up and handling literature and have the capability to utilize various literature sources and diverse retrieval tools. In the meanwhile, they should be able to process the information and materials they have retrieved and sum up them into reading reports or literature summary through their own absorption, digestion, analysis, judgment and conclusion.

\section{Conclusion}

The reform in graduate education and scientific research link should be deepened and the cultivation of their innovation capability should be dominant; in the meanwhile, the scientific research training and degree thesis of graduates should be improved. As a result, the administrative institution for graduates should be further perfected. Restrictions should be imposed on three levels, respectively supervisors, teaching administrative staff and graduates in order to enhance the graduates' capability for scientific research innovations.

\section{References}

[1] Wang Lesheng et al. Study of level administration mode for graduates [J]. Shandong Trade Unions' Tribune. 2015, (10): 115.

[2] Liu Lang. Study of channels to enhance scientific research and innovation capability of university graduates [J]. Review of Economic Research. 2016, (5): 92

[3] Ji Wei, et al. Exploration on channels to cultivate scientific research capability of university graduates [J]. Contemporary Education Research and Teaching Practice. 2016, (12): 13.

[4] Qin Nana. Discussion about cultivating innovation capability of graduates in teaching and scientific research universities [J]. Human Resource Development 2016 (06): 113. 